\title{
REHABILITATION IN A MAXILLO FACIAL AND PLASTIC CENTRE
}

\author{
By A. H. McINDOE, M.S., M.Sc., F.R.C.S., F.A.C.S.
}

The principles of rehabilitation of the sick and injured are well set out in the recent instructions issued to hospitals under the Emergency Medical Service (I942). The problem is restated in the Tomlinson Report (I942) with admirable clarity both in regard to the necessity for mental and physical reconditioning of the injured to full functional activity and the resettlement of the permanently unfit by vocational training, but with that characteristically irritating lack of detail common to Governmental reports as to how these desirable ends should be achieved. There can be no disagreement on the value of the principles enunciated, or on the advisability of their wide application, but there is much difference of opinion as to the particular methods which should be adopted.

Progress has been rapid in this field since the beginning of the war because of the greater co-ordination of hospitals, the demand for man power, and the concentration of special injuries into special departments which inevitably throws into relief problems of post-operative management otherwise lost in the general routine of the short-term' case. It is particularly in these special centres that long-term cases demanding rehabilitation are to be found. As Cairns points out, the chief impetus in this work has come from the specialist, and it is to him and to the special hospitals that we must look for the answers to many of the problems involved in the satisfactory return of the injured and crippled to industry or service. The most important contributions have come from the fields of orthopaedics (Nicoll, Watson-Jones, Houlding, Girdlestone), cranial surgery (Cairns), ophthalmic surgery (Duke Elder and Davenport), mental diseases, tuberculosis, industrial medicine (Stewart, Zimmer, Kessler), or physical medicine (Woods, Howitt).

Controversial points are many, particularly among those who would see in rehabilitation an opportunity for the setting up of a new specialty, complete with a host of experts to administer it. Should the surgeon control the patient from the date of injury to the time of his return to service or industry, or should he be handed over to a rehabilitation expert from the ranks of physical medicine as soon as the wound is surgically healed? Are special centres necessary for different types of injury or disease, or can any injury be satisfactorily handled in a standard type centre? How far is it possible to deal with the entire problem within the same hospital in which the patient is surgically treated? The orthopaedic surgeon obviously prefers the special remedial centre in which stress is laid on remedial exercises, physical training, and organised games. The cranial surgeon would accept the communal rehabilitation centre for service cases, but sees little value in it for civilian injuries, preferring the supervision afforded by the out-patient department of a head centre and the environment of the home. Ophthalmic rehabilitation is obviously governed by the fact of recoverable or irrecoverable vision, St. Dunstan's being a brilliant example of the value of centralised treatment in the latter class. Few surgeons see any virtue in the divorce of the convalescent handling and reconditioning of the patient to the re-employment stage from the actual treatment of the surgical condition. The physical therapist, however, thinks otherwise. He feels this to be the legitimate field for the full exercise of his art.

It is at least obvious that there is no such thing as a standardised course of rehabilitation which will, on the one hand, enable a pilot with both legs amputated to return to his flying with added distinction, and, on the other, make an efficient operative at the coal face out of a miner with a fractured femur. It is equally certain that a different quality of rehabilitation must be established for the miner with a fractured femur and the factory hand with the same condition, whose work is sedentary. The type of rehabilitation which would be successful in these three cases would almost certainly fail to return to the ranks of medicine a former third-year medical student, now aircrew, with severe disfiguring facial injuries and crippled hands resulting from burns, involving a programme of two years of hospital life and ten to twenty operations. What is a suitable regime for one patient may be disastrous for another.

The surgeon whose sense of responsibility is limited by good surgery and conscientious postoperative treatment to the point where anatomical restoration and a clean wound are produced, will fall far short of the desired end. Similarly, the physical therapist who inherits the patient and whose vision is bounded by a galvanic battery, a wax bath, a variety of lights, and a set of 
remedial exercises, will likewise fail. Whoever accepts this wider conception of the medical ideal, must realise that the return of an individual to normal life and work depends on the successful restoration of the injured part, together with its functional re-education, the maintenance of general muscle tone, the maintenance of a high state of mental alertness during the total period of disability and, finally, the placement of the patient in work to which he is accustomed and which he is able to perform. Alternatively, through vocational training, he must be fitted for other work in which he can achieve economic independence.

Sober consideration and some experience lead one to the conclusion that, in truth, the physical therapist, with his fairly limited endeavour, must play a minor and not a major part, that he can be an accessory but not a principal, that he can help but not direct the course of this complicated regime. Ideally, the best results can only be obtained by the surgeon who interprets his duty to the patient in the widest sense. The measure of his success will be judged by the proportion of his true "end results," returned to efficient work. The qualities demanded of him are many, and the strain upon his time and energy great. He must be a good surgeon in the accepted sense, with an intimate knowledge of convalescent treatment and physical medicine in all its branches, he must know factory conditions, something of industrial processes, and much of the technical side of Army, Navy and Air Force life. He must be a good psychologist, and exhibit a profound curiosity in all that dnimates the lives of his patients. It matters little whether his psychiatric attitude is natural or acquired. He should have a wide circle of friends and acquaintances in the neighbourhood of his hospital, for there is no escaping the fact that a powerful and beneficial influence can lie in the interest which the surrounding community can display, particularly if it is properly guided and controlled. When the milk of human kindness disappears in the bureaucracy of a State Medical Service, irreparable harm will be done to the future of medicine.

A plastic surgery and maxillo facial centre offers unique opportunity for the study of rehabilitation problems, because of the high percentage of long-term cases, the wide variety of conditions treated, and the psychological difficulties which the patients present.

\section{Long-Term versus Short-Term Cases.}

The definition of a long-term case is not easy. Measured in terms of bed occupation, it would appear that the really chronic patient is distinctly in the minority; thus, of 770 consecutive surgical cases admitted during I942, the following table shows the actual periods of stay within the hospital:

$$
\begin{aligned}
& \begin{array}{llllllll}
\text { I-6 weeks } & \ldots & \ldots & \ldots & \ldots & \ldots & \ldots & 67 \%
\end{array} \\
& \begin{array}{lllllll}
\text { 7-I4 weeks } & \ldots & \ldots & \ldots & \ldots & \ldots & 19.7 \%
\end{array} \\
& \begin{array}{lllllll}
\text { I5-26 weeks } & \ldots & \ldots & \ldots & \ldots & \ldots & \text { I0.7\% }
\end{array}
\end{aligned}
$$

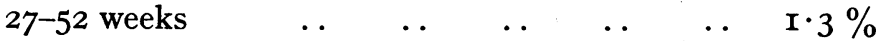

$$
\begin{aligned}
& \begin{array}{lllllll}
\text { over } 52 \text { weeks } & \ldots & \ldots & \ldots & \ldots & \ldots & \mathrm{I} \cdot 3 \%
\end{array}
\end{aligned}
$$

This, however, does not represent by any means the total period of disability, but rather the time required for the satisfactory performance of the actual operations. As will be seen, much of the convalescent time is spent outside the hospital. A patient, for instance, who spends six bed weeks in hospital is rarely fit for duty under six months, and sometimes longer. Experience shows that considerably more than half the patients require some form of rehabilitation, while practically all of them benefit from a well-planned regime.

\section{Types of Injury.}

In the above series, approximately 50 per cent were facial injuries, largely burns, facial fractures, and soft tissue defects, while 5o per cent concerned the rest of the body in the form of skin losses from trauma, soft tissue contractures and deformities, mostly of orthopaedic significance. Thus, in the former group, while the question of function is of importance, the patient himself is usually fit, and the major problem is a psychological one. In the latter group functional re-education is paramount. To be successful, therefore, the whole scheme of rehabilitation must be designed to cater for a variety of requirements. It must contain those elements necessary for the maintenance of mental alertness in the disfigured patient and sufficient physical reconditioning to restore function in the crippled. 
The Psychological Problem.

The impact of disfiguring injuries upon the young adult mentality is usually severe. The majority have been strong and healthy, and have given no consideration to illness or injury, nor to its possible future effects. They are usually unprepared mentally for the blow, so that for a period they may be psychically lost, depressed, morose, pessimistic, and thoroughly out of tune with their surroundings. It is difficult to gain their confidence or to convince them that they can be of use in the world. They believe that their former social status and facility of performance are at an end, that they are no longer marriageable, and must remain only as objects for well-meant but misguided pity. Often this attitude of mind is hidden beneath an apparently normal outlook, only to show itself eventually by a complete lack of adjustment to life when the repair phase is finished and employment is attempted. The mental problem is not so severe with orthopaedic injuries, but it does exist and must be combated.

\section{FUNDAMENTALS OF A SCHEME OF REHABILITATION DEVELOPED IN}

\section{A MAXILLO-FACIAL AND PLASTIC UNIT}

\section{Physical Plant.}

Nothing is more conducive to a cheerful outlook than pleasant comfortable surroundings. Hence, every effort has been made to convert the three standard E.M.S. hutted wards (9o beds) comprising the Unit into attractive living quarters. The original emergency beds were discarded and good modern hospital beds installed. This was done by a simple borrowing from another hospital not now in use. The depressing dark brown and cream decorative scheme so beloved of the Office of Works was changed to a gayer combination, and bright curtains were added. There are always fresh flowers in the wards. Concrete runways were laid down outside each ward so that on fine days the beds can be taken outside. The total effect is one of lightness, freshness, and restful colour. There are ${ }_{8}$ no cubicles or private rooms. Officers, ranks, and civilians occupy adjoining beds without distinctions and without difficulty. By careful thought and inexpensive alterations, it is possible to remove from the most unattractive buildings that institutional atmosphere which is the curse of much hospital life. It is unnecessary to strive for that marble elegance quite out of touch with the ordinary lives of the patients who pass through the hospital. Within 25 years a hospital is out of date and requires rebuilding. Therefore it should be of simple but thoroughly modern construction in tune with the times during which it is used.

The nursing and orderly staffs are carefully chosen, efficient, and when once adapted to this special work are not shifted from ward to ward more than is absolutely necessary. Ward rules are reasonable and reasonably applied.

To these three huts have been added the following amenities:

(a) Three recreation huts for officers, ranks, and women. All these are large, comfortably furnished and effectively decorated.

(b) Dining rooms, rest, and reading rooms.

(c) Physiotherapy, occupational therapy, and industrial therapy departments.

(d) A convalescent annexe of fifty beds adjacent to the wards.

The hospital has ample recreational grounds, and is outside a country town with good facilities for amusement. All wards and departments are linked by a broadcasting system used for music, concerts and lectures, as well as for the daily bulletins of local news and announcements. This is a feature found in many hospitals, but it would appear to be used mainly as a means of summoning staff members rather than as a most useful adjunct to general hospital life.

\section{The Atmosphere.}

Of no less importance than the standard of physical comfort is the atmosphere which pervades the hospital. This indefinable quality must radiate from the staff. It is generated by enthusiasm for work, by satisfaction born of being a member of an efficient team, by anxiety for the patients' welfare, and by devotion to duty tempered by optimism, tact, understanding, and good humour. The intelligent patient is quick to notice and quicker to respond to this atmosphere.

These two factors of physical and spiritual value are mentioned merely to emphasise the 
important, but often forgotten, fact that the injured, disfigured and depressed patient reacts strongly to his environment. It is well to ensure that his preliminary reaction is a favourable one.

\section{The Maintenance of Mental Alertness.}

In such a hospital this is a major problem. It has been attacked in a variety of ways, some successful, others less so. The difficulty is to combat boredom in patients whose powers of mental concentration are seriously reduced, and who are at the same time going through a period of severe mental turmoil. Purely diversional pursuits are useful here, such as films, concerts, picnics, and outings with simple ward handicrafts designed to occupy hand and mind pleasantly. In the early stages, intellectual exercises rarely succeed. Education of the factual variety (languages, book-keeping, technical reading, etc.) failed because of this lack of concentration and the broken time available for it. But interesting talks by well-known speakers, lectures on subjects of topical interest, internal discussion groups, and a "brains trust" have proved most successful. Books and music are two important factors which deserve consideration. Most hospital libraries are composed of books which no one else wants. They should be ruthlessly overhauled and about 90 per cent sent for salvage. There is an open library, both technical and non-technical in each of the recreation and rest rooms, which is small, carefully selected, and added to regularly by the current "books of the month" and by other selections. Books of this sort are really used. The daily papers and current periodicals should be available so that patients can keep abreast of the times. Music lovers fall naturally into two groups, those who like good music and those who prefer jazz. The usual hospital gramophone is a murderous piece of machinery. Good music is only enjoyable when played on a good instrument, hence efforts were made to secure the best records and a first-class self-changing radiogram, which can be played in a quiet room to an appreciative audience. The result is that more and more patients prefer Beethoven, Chopin, or Brahms to the works of Mr. Benny Goodman. It must be recorded, however, that there are many who remain faithful to a steady undercurrent of syncopated noise, whether they are eating, dressing, working, or even sleeping.

\section{Welfare Officer or Field Worker.}

All these activities require organisation. Purposeless amusement is of little benefit to the patient, and can be a great waste of time and money. The existence of a multitude of facilities does not in itself maintain that state of mental alertness which is so desirable. The facilities can only be effective in so far as they are used as tools by a person specially selected and trained to use them. A Welfare Officer was therefore appointed, who lives with the patients in the convalescent annexe. He learns the intimate difficulties of each patient, and, on the basis of understanding and sympathetic insight into the various problems, prescribes and organises a course of activity aimed at mental rehabilitation. He has wide powers to act and, if necessary and after consultation with higher authority, money to spend. This is not a field for the professional psychiatrist, nor can doctors, educational officers, or padres cope with it. In addition to the study of individual cases, the Welfare Officer arranges the daily round of events, and sees to it that neither too much nor too little takes place on any one day. $\mathrm{He}$ acts as a leader in games, picnics, outings, and other group activities. The field worker has become indispensable, and should be attached to every hospital and rehabilitation centre where this problem exists.

\section{Functional Re-education and maintenance of General Mưscle Tone.}

This is altogether remedial and requires medical control. It follows closely the principles laid down by Watson-Jones, Houlding, Nicoll, and others, for orthopaedic injuries, and involves physiotherapeutic measures, repetitive remedial exercises, and organised games.

\section{Physiotherapy Department.}

Most of the patients treated here are recently healed burns, recent grafts, or crippled hands and legs. The work of the masseuse includes light massage to soften grafts, deep massage for the dispersal of static or reactionary oedema, and the improvement of muscle tone, particularly after soft tissue injuries awaiting repair. The crippled burned hand requires daily a directed course of repetitive exercises after a preliminary paraffin wax bath, but contrary to Houlding's 
experience, splints are very rarely used. All manipulation and forced movements of stiff fingers are forbidden. With the improvement in burn treatment, the patients should come to the masseuse with the fingers not straight, but in a functional position of grasp. From this position, movement is encouraged. Light treatment, except as a general tonic, is rarely used, and radiant heat on recently burned or grafted skin is a positive danger, as the surface is insensitive and blisters with great ease. If peripheral heating is advisable, a short-wave coil round the thigh or upper arm proximal to the damaged area can be used to heat the blood going to the part. A rise of $\mathrm{I}-2^{\circ}$ can be efficiently maintained.

Most of the work here, however, is directed towards making the patient work for himself. Hence, for burned hands a rubber sponge, rubber balls and rubber rings become from early stages part of the patient's personal equipment. This begins in bed as soon as he is capable of grasping anything, and it is carried on until he can begin occupational work. In the lower limb, quadriceps drill is instituted early, beginning with the galvanic stimulus, and later working to active exercise against resistance. As soon as possible, however, the patient is passed from the physiotherapy department to the occupational workshop. The limitations of a physiotherapy department must be realised, for too many patients are sent there, either as a method of getting rid of the patient, or in a vain hope that the more elaborate the equipment, the more brilliant will be the results.

\section{Occupational Therapy.}

In the generally accepted sense, this means cane work, leather work, bookbinding, weaving, carpentry, etc. Admirable work in itself and useful for certain patients, it has been found under war conditions to have a restricted field. Early in the war the hospital was equipped with a complete department of this description with a trained occupational therapist in charge. After working a year it was found that less than 5 per cent of the patients who should be working were actually doing so. Absenteeism was rife, and interest was lacking. The reasons were not far to seek. The work has little essential meaning, especially at the present time; it is frequently merely diversional, and other interests conflict with it. Service personnel found it childish and worked only under extreme pressure. Often it was found that having made one bag or cane basket, the patient did not try another. The department was therefore scrapped and turned into what might be called a remedial workshop or Industrial Therapy Department. This is a full-scale factory for the assembly of aircraft precision instruments. With the help of a well-known instrument manufacturing firm, machine tools were installed (drills, lathes, and presses) with benches fitted with all necessary apparatus, for twenty-five workers. This was carried out to the most modern requirements. The benches were arranged in groups. Constant supplies of parts arrive weekly from the parent factory, and are assembled by the working patients under the direction of a head technician supplied by the factory, and four girl workers, one of whom sits at each bench as instructor. Nine separate assembly jobs are handled, and each can be learnt in a few hours. The work is clean, interesting, and of great remedial value, particularly for crippled hands. The patients feel that it is of national importance. To avoid monotony, the workers change places so that several operations are learnt. Work is carried on daily in shifts of four hours, so that fifty patients can be accommodated per day. The response was immediate and lasting, and the staff cannot cope with the demands made upon it. It is believed to be the first hospital factory of this type in the country. The industrial surgeon must examine carefully this valuable adjunct to his rehabilitation programme.

It is of interest to note that the production of many patients with crippled hands and good mentality often exceeds that of patients with undamaged hands but of duller intellect. Personality maladjustments can play a more important role in working capacity than physical deformity. Organic defects, on the other hand, may act as a stimulus to achievement so as practically to eliminate the defect from consideration. That acute observer, Charles Mayo, once remarked that it would be a good thing if all house surgeons during their tenure of office had a club foot. They would dance less and work harder!

In this particular centre there is no question as to the relative value of productive work of this kind over that of the handicraft type. It would be interesting to know in these days of shortage of manpower how much latent and willing energy lies awaiting development in our hospitals and institutions.

There is still a field for handicrafts, however, particularly in the wards, where patients are 
immobilised in bed for long periods. These are of the usual kind and require no comment. Once the patient is out of bed, something more serious is indicated.

\section{Organised Exercise and Games.}

With such a variety of injuries and so many patients with recent grafts, including painful areas from which extensive sheets of skin have been removed, it is very difficult to run P.T. classes or organised games. A football team and a cricket team have played regularly and successfully, however, though few of those who probably need this sort of activity most have been able to take part. Organised walks, bicycle rambles, and picnics are more useful, but must be carried out under the direction of the Welfare Officer. Here, too, haphazard arrangements are hopelessly inadequate, and there must be a leader.

\section{Interim Employment.}

A considerable number of patients in these plastic centres require multiple stage operations with a period of rest and recuperation between each stage. Not all this time is spent in hospital. In fact, it is most advantageous to get the patient out at the earliest possible moment. His disposal during this period was at one time difficult, for while a certain number can be returned temporarily to service life, many are unsuited for it. To meet this problem in the R.A.F., a scheme of interim employment was arranged with the co-operation of the Ministry of Aircraft Production, by which patients were placed in factories for work carefully chosen to suit the individual case. Sixty factories form the basis of this scheme, each varying slightly in the type of work available. The men work a prescribed number of hours at selected jobs, and do so in uniform. The advantages are that the patient does work of a remedial nature and of national importance, and at the same time has an early opportunity of breaking down the inferiority complex resulting from his disfigured appearance by mixing freely with his fellowmen. As might be expected, the effect of this upon the productive capacity of many of the other workers has been stimulating. The disadvantages of the plan are the difficulties of control, the question of billetting and posting. This has been largely solved by the establishment of a special department under the Air Ministry to deal with it.

\section{Final Placement.}

With this extensive programme of rehabilitation, it is obvious that the surgeon in charge develops a deep interest in the welfare and progress of his patients. When the time comes for return to service or industry, he is likely to see to it that the man who has been reconditioned mentally and physically is placed in the correct niche and not thrown willy-nilly on to the labour market. Employers of labour and heads of service departments are only too eager in these times to adjust the job to the man, or vice versa. Hence, close touch must be maintained with the patient and with his employers until it is clear that he can stand on his own feet. It must be remembered that these conditions may not always persist when the demand for labour is not so acute, hence it is vitally important to maintain an efficient follow-up scheme and to check from time to time the patient's progress. It may be found, for instance, that a new form of work is desirable, and that vocational training is required. It is, I believe, not part of the duty of a hospital to undertake work of this sort, and it is much better handled at a training centre such as those mentioned in the Tomlinson Report, or others set up by the Ministry of Labour. It would be in the best interest of the patient, however, if the hospital and the training centre maintained intimate contact so that all available informatipn concerning the patient is directed to the same desirable end.

\section{SUMMARY}

I. The return of an injured individual to normal life and work depends on the successful restoration of the injured part, its function and re-education, the maintenance of general muscle tone and mental alertness, and the final placement of the patient in industry or service as an independent economic unit or an efficient soldier, sailor, or airman.

2. Rehabilitation of patients requiring plastic repair is an essential part of treatment. It must be a carefully planned prescription embodying both psychological and physical remedial ingredients. 
3. The responsibility for this should be with the surgeon. In the physical field the physiotherapist and occupational therapist can help; in the psychological field a trained field worker (male) who lives with the patients is a necessity. He acts as investigator of individual difficulties, organiser and leader in all group activities.

4. Physiotherapy and occupational therapy have a limited field in Rehabilitation. Repetitive remedial exercises leading to carefully selected industrial therapeutic employment are more important.

5. A scheme of industrial work within the hospital is described, which has given excellent results, and which has largely displaced occupational therapy of the old-fashioned kind. scheme.

6. Interim employment in selected factories has been found to be a useful adjunct to this

\section{BIBLIOGRAPHY}

EMERGENCY MEDICAL SERVICE INSTRUCTIONS.-Preparing sick and injured for return to work. Ministry of Health. Bull. War

Med., r942, 2, 43I-432 (May).
CAIRNS, H., Rehabilitation after head Injuries. Brit. J. Phys. Med. I942, 5, 84 (May-June).

DUKE ELDER, LADY and DAVENPORT, R. C., Rehabilitation in Ophthalmic Cases. Brit. J. Phys. Med., I942, 5, p. 88 (May-June).

GIRDLESTONE, G. R., Occupational therapy for wounded. Brit. J. Phys. Med., 1942, 5, $91-93$ (May-June).

HOULDING, R. N., Rehabilitation of injured air crews. Brit. Med. J., r941, 2, 429-433 (September 27).

HOWITT, F. D., Rehabilitation and the War. Brit. J. Phys. Med., I942, 5, (May-June).

KESSLER, H. H., Rehabilitation of the physically handicapped. Sth. Surgeon, I940, 9, 34-40 (January).

NICOLL, E. A., Rehabilitation of the injured. Brit. Med. J., I941, 1, 50r-506 (April 5).

STEWART, D., Rehabilitation of injured workmen, with special reference to Workmen's Compensation Act. Lancet, r939, 1, r29-132 (January 2r).

TOMLINSON REPORT.-Report on Inter-Departmental Committee on the Rehabilitation and Resettlement of Disabled Persons. January

WATSON-JONES, R., Rehabilitation in the Royal Air Force. Brit. Med. J., 1942, 1, 403-407 (March 28).

WOODS, R. S., Rehabilitation in the E.M.S., Brit. Med. J., 1942, 2, 89-90.

ZIMMER, V. A., Rehabilitation and Workmen's Compensation. N.Y. St. J. Med., I941, 41, 1057-1060 (May 15).

\section{ANAESTHESIA FOR ABDOMINAL SURGERY IN ADULTS}

By HELEN BOWER ALCOCK, M.R.C.S., L.R.C.P., D.A.

(Anaesthetist, Soho Hospital for Women; Anaesthetist, French Hospital; Clinical.Assistant in Anaesthetics, West London Hospital, etc.)

The chief methods of anaesthesia available for abdominal surgery in adults are five:-

(I) Nitrous oxide-oxygen with ether or chloroform.

(2) Cyclopropane-oxygen.

(3) Spinal anaesthesia.

(4) Continuous pentothal sodium-nitrous oxide-oxygen.

(5) Local anaesthesia.

I propose to refer briefly to the first three. The last two I consider methods of choice, one or other of which is applicable to the majority of cases: they will be dealt with in some detail.

\section{Nitrous oxide-oxygen with ether or chloroform}

Chloroform is little used nowadays, but nitrous-oxide-oxygen-ether is still the most popular anaesthetic combination. Its advantages are:

(I) that complete relaxation of the abdominal muscles is obtainable without having to push the ether unduly, and

(2) that the signs of anaesthesia are clear and well-defined at the various stages so that for the infrequent anaesthetist it is undoubtedly the safest anaesthetic.

Nevertheless its disadvantages are such that every effort should be made to replace it by agents less toxic, less irritant, and attended by less unpleasant sequelae. We are fortunate that recent advances in ànaesthesia have provided us with satisfactory alternatives. 